\title{
Modeling and Prediction Overview
}

\author{
D.L. Ermak
}

October 18, 2002

U.S. Department of Energy

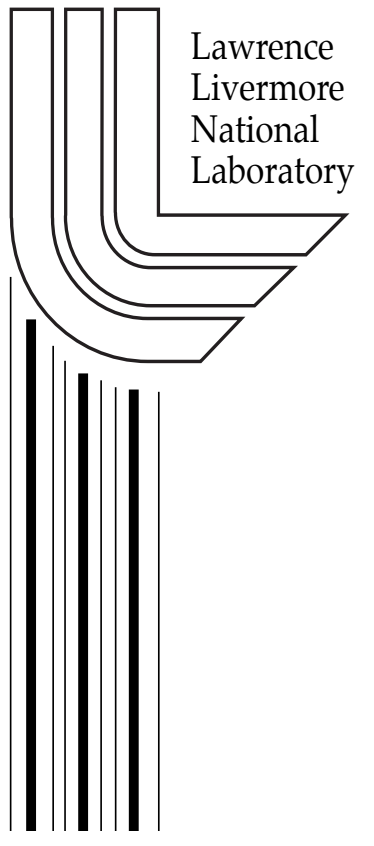




\section{DISCLAIMER}

This document was prepared as an account of work sponsored by an agency of the United States Government. Neither the United States Government nor the University of California nor any of their employees, makes any warranty, express or implied, or assumes any legal liability or responsibility for the accuracy, completeness, or usefulness of any information, apparatus, product, or process disclosed, or represents that its use would not infringe privately owned rights. Reference herein to any specific commercial product, process, or service by trade name, trademark, manufacturer, or otherwise, does not necessarily constitute or imply its endorsement, recommendation, or favoring by the United States Government or the University of California. The views and opinions of authors expressed herein do not necessarily state or reflect those of the United States Government or the University of California, and shall not be used for advertising or product endorsement purposes.

This work was performed under the auspices of the U. S. Department of Energy by the University of California, Lawrence Livermore National Laboratory under Contract No. W-7405-Eng-48.

This report has been reproduced

directly from the best available copy.

Available to DOE and DOE contractors from the

Office of Scientific and Technical Information

P.O. Box 62, Oak Ridge, TN 37831

Prices available from (423) 576-8401

http: / / apollo.osti.gov/bridge /

Available to the public from the National Technical Information Service

U.S. Department of Commerce 5285 Port Royal Rd., Springfield, VA 22161

http://www.ntis.gov/

OR

Lawrence Livermore National Laboratory

Technical Information Department's Digital Library

http:/ / www.llnl.gov/tid/Library.html 


\title{
Modeling and Prediction Overview
}

\author{
Donald L. Ermak, Lawrence Livermore National Laboratory \\ (925) 423-0146, email: ermak1@llnl.gov
}

\section{Objectives}

Effective preparation for and response to the release of toxic materials into the atmosphere hinges on accurate predictions of the dispersion pathway, concentration, and ultimate fate of the chemical or biological agent. Of particular interest is the threat to civilian populations within major urban areas, which are likely targets for potential attacks.

The goals of the CBNP Modeling and Prediction area are:

- Development of a suite of validated, multi-scale, atmospheric transport and fate modeling capabilities for chemical and biological agent releases within the complex urban environment

- Integration of these models and related user tools into operational emergency response systems

Existing transport and fate models are being adapted to treat the complex atmospheric flows within and around structures (e.g., buildings, subway systems, urban areas) and over terrain. Relevant source terms and the chemical and physical behavior of gas- and particle-phase species (e.g., losses due to deposition, bio-agent viability, degradation) are also being developed and incorporated into the models. Model validation is performed using both laboratory and field data.

CBNP is producing and testing a suite of models with differing levels of complexity and fidelity to address the full range of user needs and applications. Lumped-parameter transport models are being developed for subway systems and building interiors, supplemented by the use of computational fluid dynamics (CFD) models to describe the circulation within large, open spaces such as auditoriums. Both sophisticated CFD transport models and simpler fast-response models are under development to treat the complex flow around individual structures and arrays of buildings. Urban parameterizations are being incorporated into regional-scale weather forecast, meteorological data assimilation, and dispersion models for problems involving larger-scale urban and suburban areas. Source term and dose response models are being developed for use in the transport models. "Rules of thumb" provide guidance to emergency responders in situations when immediate response is necessary and model simulations are not available.

These modeling capabilities and tools are being integrated into operational systems for planning and training, real time emergency response, and post-event consequence analysis. CBNP interior modeling tools are directed in large part toward implementation into the PROTECT system for $\mathrm{CB}$ defense of interior infrastructure facilities. CBNP's exterior modeling tools for treating CB releases within the urban environment are integrated into the existing DOE National Atmospheric Release Advisory Center (NARAC), which provides real-time atmospheric hazard assessments. Internet and Web based software tools provide authorized users with secure remote access to the operational NARAC system. NARAC plume dispersion and health-risk predictions, as well as recommended actions, aid emergency managers and first responders in coordinating multi-agency responses. 


\section{FY02 Highlights}

Model development and evaluation are long-term processes. As individual models mature, they are integrated into operational systems, which in turn are developed and evaluated. Significant progress has been made in all three components of effort during FY02.

The systems integration team integrated CBNP M\&P developed CB urban models into the NARAC central system. Urban versions of NARAC's models have been coupled to global landuse, population, chemical and biological material properties, source scenarios, and health risk level databases to generate value-added products, such as population exposures, affected areas and recommended protective action guidelines. Predictions are overlaid on aerial photographs, map images, and multiple geographical information layers including information on important public facilities. Summary reports describe the assumptions used in the simulations as well as interpretive information. These CBNP-developed NARAC capabilities were extensively used for threat-response support during the heightened alert following the events of September 11, 2001.

NARAC Internet and Web remote access tools (the NARAC iClient and Web) support an expanding set of local, state, and federal agency customers. This software is being used operationally at a number of DOE sites. NARAC is also participating in pilot projects underway in Seattle (CBNP LINC DDAP) and Albuquerque (Defense Threat Reduction Agency's Biological Defense Initiative) to develop approaches for supporting local emergency management agencies and responders using these tools. Recently added iClient features include combined local rapid-response and advanced reach-back modeling capabilities, situation awareness tools, and new value added products, which provide additional guidance to end users and emergency responders. Wind observation and model generated wind-field displays are available. A field measurement tool (Figure 1) allows the user to enter, transmit, and display sampler data, and probe the plume to determine the model-predicted concentration at any given point. Comparisons with field measurement data can be used to refine NARAC predictions and develop sensor siting plans.

$<$ Insert Fig 1. tiff>

Figure 1. NARAC products and situation awareness displays include plume predictions, field measurement locations indicated by station number, and detailed maps.

Model evaluation requires the availability of high quality data from field-scale experiments. A major accomplishment of the urban field studies team was the documenting and release of data from CBNP's urban meteorology and tracer field campaign conducted in Salt Lake City, Utah, during October 2000. An overview of the URBAN 2000 field study was published in the Bulletin of the American Meteorological Society (Figure 2) and the field data from the study is being widely used for evaluation of urban dispersion models. In other field study efforts, CBNP investigators are using the data from the DoD's Mock Urban Simulation Trials (MUST) conducted in September 2001, for model evaluation and investigations of processes governing dispersion in urban environments. The planning for the next major urban field campaign (JOINT URBAN 2003), to be conducted in Oklahoma City in collaboration with the DoD Defense Threat Reduction Agency during July 2003 is well underway. Numerous investigators from U.S. 
federal laboratories (DOE, NOAA and DoD), foreign laboratories (U.K. Defence Science and Technology Laboratory and Canadian Defence Research and Development Laboratory), universities, and private companies will collaborate in the Oklahoma City study.

$<$ Insert Fig 2. tiff>

Figure 2. Cover of the April 2002 issue of the Bulletin of the American Meteorological Society featuring the URBAN 2000 field study. The figure shows a tracer plume in downtown Salt Lake City, Utah.

In the past year, the focus of the building-to-urban scale modeling teams has been in model validation and the analysis of the meteorological and concentration data collected from the URBAN 2000 field experiment in Salt Lake City. Although the validation studies have been quite challenging due to the variability of the wind conditions during the experimental periods, successful comparisons between model results and data have been achieved (Figure 3). Approaches for reducing the computational costs of the high fidelity (CFD) building scale models are being explored, in order to develop cost-effective modeling capabilities which can be integrated into emergency response systems for near real-time applications. Empirical buildingscale models are also being developed (QWIC-URB, QWIC-PLUME) for stand-alone fast response applications.

$<$ Insert Fig 3. tiff>

Figure 3. The FEM3MP CFD model dispersion pattern from an URBAN $2000 \mathrm{SF}_{6}$ point release in Salt Lake City.

Following the events of 9/11, there have been many requests from various government agencies to assist in modeling scenarios of biological and radiological terrorist attacks on their facilities. Leveraging capabilities derived from prior CBNP efforts, the CBNP urban modeling teams have simulated agent clouds dispersing around specific government buildings under predetermined scenarios. CBNP models used in these studies included the fast response QWIC-URB, QWICPLUME, and Urban Dispersion Model and the high fidelity HIGRAD and FEM3MP CFD models. Other examples of recent applications of these models include developing scenarios for synthetic studies, planning strategies for coping with emergencies at special events, and performing vulnerability analyses and mitigation strategy studies for specific sites. 
The transport of CB agents over large distances must be handled by regional atmospheric codes. These codes do not "see" the buildings explicitly because the spatial resolution, or grid size, of the models is on the order of a kilometer. Urban canopy parameterizations have been developed by the regional-scale exterior modeling team that allow the atmospheric models to simulate the area-averaged effects of the buildings without explicitly resolving them (Figure 4).

<Insert Fig 4Frame1.gif and Fig4Frame2.gif >

Figure 4. Modeled (dashed) and observed (solid) SF6 concentration with (left) and without (right) the urban parameterization in regional-scale COAMPS weather forecast model simulations. Mechanical and thermal forcing due to the urban area affect the mean flow and the turbulence, and ultimately the dispersion of the tracer.

The urban canopy parameterizations require input parameters that describe the building density, size, shape, and other characteristics. Automated routines that work inside of popular GIS software have been developed for analyzing this data and deriving the building statistics needed in urban parameterizations (Figure 5). Analyses have been completed for nearly 40,000 buildings in 5 western US cities and in the coming year 5 eastern US cities will be analyzed.

$<$ Insert Fig 5.gif >

Figure 5. A three-dimensional database of downtown Los Angeles. Building statistics needed for transport and dispersion simulations can be efficiently derived from this data.

The building interiors team develops and experimentally tests transport and fate models for CB agent dispersal in buildings. These models are then used to provide guidance and training to first responders, building managers, and owners for protective measures, mitigation and emergency response. The project effort in FY02 developed training manuals, providing advice to first responders. A website was set up to offer more detailed information and advice to interested building managers and operators and first responders. Experimental research on aerosol transport across the building envelope and through building HVAC systems was completed. Computational research demonstrated predictive power for assessing mixing-time for pollutants in single indoor spaces under isothermal, mechanically mixed conditions. An algorithm to synthesize and interpret data streams from multiple sensors was developed and applied to interpret sensors monitoring airborne toxic chemicals indoors. Finally, advances were made towards adding a capability to LLNL's NARAC model for predicting indoor concentrations and exposures in residential communities resulting from a toxic plume release outdoors (Figure 6). 
$<$ Insert Fig 6.tiff >

Figure 6. A NARAC simulation grid (blue) for an outdoor plume prediction is overlaid on a color-coded map of the Salt Lake City region. The color codes, ranging from yellow to red, illustrate the mean year in which homes in each county were built. The housing age data can be automatically extracted from census information to calculate indoor concentrations resulting from the outdoor plume.

A major focus of the subway modeling team was the development of a rapid-response model, which treats the three key elements of subway systems dispersion - train induced flow, natural flows (driven by the coupling of the underground system to the outdoor meteorology), and transport by uptake and discharge in train cars. An early milestone in this effort was achieved in November 2001 with the completion of a model with 3-5 second run times that can predict flow and dispersion in a single subway line consisting of several stations connected by one or more tunnels. This initial model became part of the CB-EMIS emergency response architecture exercised in the December 5, 2001, CBNP PROTECT technology demonstration. Subsequently, this model has been extended to simultaneously calculate flow and dispersion in multiple subway lines, including exchange between lines at crossover stations.

The primary experimental thrust for the subway modeling team has been the measurement and characterization of natural flows (Figure 7). Four meteorological packages were installed within a subway system in November 2001 providing continuous 10-hz velocity, temperature and pressure data throughout 2002. To supplement these measurements, temperature data are being collected at 29 additional locations in 4 stations, and hundreds of hours of flow data have been collected at entrances to over 20 stations during normal revenue operation. Altogether, these data have clearly demonstrated that significant natural flows are present in the system under study, both during normal train operation and when trains are stopped. A clear correlation between natural flows and the external meteorology exists. Additional experimental work focused on (a) completing experiments in the 1/29-scale laboratory subway station model and (b) analysis of data from the June 2002 station smoke experiments conducted at four subway stations in Washington DC.

$<$ Insert Fig 7.tiff>

Figure 7. One of four meteorological stations recording environmental data (wind, temperature and pressure) in a subway system for natural flow characterization.

The source term and dose response team is developing models of terrorist type sources, the physiological effects of the agents on the general populace, and the viability of threat agents in the environment. Two key elements are the Source Term Encyclopedia and the Data Response models. The Source Term Encyclopedia is a spreadsheet-based model employing validated 
correlations, which are used to estimate the source term arising from dissemination of a given agent by a selected dispersal method. The source term includes the dispersal method, the agent type, the amount of agent and its state (gaseous, particulate, or both), the size distribution, and the time-varying source rate. The Dose Response models include the effects of various levels of exposure on the general public. An important part of this work is the development of dose response parameters for the general population using data derived for a healthy military population. Estimates have been made for nerve agent toxicity for the general population for two and ten minute exposures. Figure 8 shows the dose response curves for the fraction of the population killed by a two minute exposure to the agent GB (sarin). The two curves are for a healthy population and for the general population.

\section{<Insert Fig 8.jpg>}

Figure 8. Dose response for healthy and general populations from a two-minute exposure to sarin.

The final CBNP M\&P tasks were to assess the needs and capabilities of users of atmospheric transport and dispersion models for chemical or biological (CB) agent releases, and to develop a comprehensive set of urban model evaluation methodologies. The final report on user needs was completed this year. The report summarizes the types of users of CBNP atmospheric transport and dispersion models and includes analyses of responses by users to a questionnaire. Histograms compare the responses of users to the various categories of questions, showing for example, the desire for short training times, simple weather inputs, detailed users guides, on-line help and capability to easily plot contours. On the model evaluation methodologies task, methods being developed are intended to include scientific evaluation criteria, statistical evaluation procedures, guidance for communicating results and uncertainties to decision-makers, field and laboratory data sets, and applications of evaluation methods to a few field databases as demonstration exercises. Efforts this year have been devoted to acquiring and analyzing urban field data sets (such as URBAN 2000) and to modifying the BOOT model evaluation software to include several new approaches and performance measures, such as the ASTM and the MOE approaches.

\section{Impact}

CBNP-developed Modeling and Prediction capabilities are unique and provide users in the intelligence, law enforcement, and emergency management communities with enhanced capabilities to protect U.S. citizens. Validated models of the flow, chemistry, transport and toxicity/viability/health-hazard of materials within urban areas, combined with improved detection and communication of results to users, will greatly improve incident response capabilities.

The CBNP models can be utilized in planning, training, emergency response, and post-incident analysis. Planning analyses provide users with information to determine optimal sites for emergency assets and evacuation routes. During an incident, models predict the downwind hazard and safe zones. Following an incident, model analyses can be used to reconstruct events and aid in identifying exposed populations. 


\section{Next Steps}

CBNP is developing an integrated system of atmospheric transport and fate models that is both state-of-the-science and meets the needs of emergency managers and first responders. Model validation efforts will be emphasized, including comparison of data from existing and planned field and laboratory experiments. Model development will continue in order to improve the representation or parameterization of physical processes as dictated by these data comparisons. Operational systems will be enhanced to provide authorized users with easy access to highquality model predictions and new value-added products. 
Figure 1.

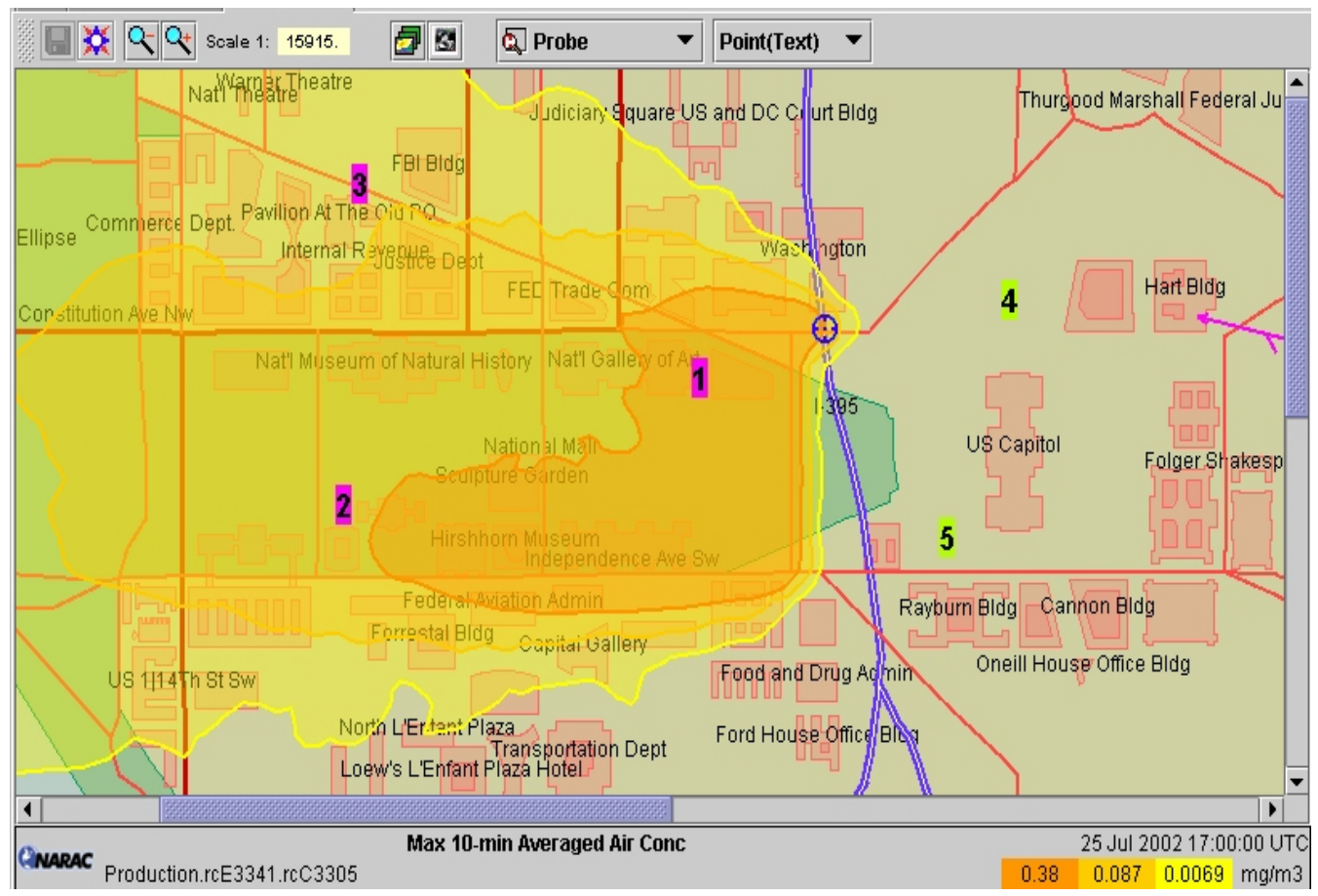


Figure 2.

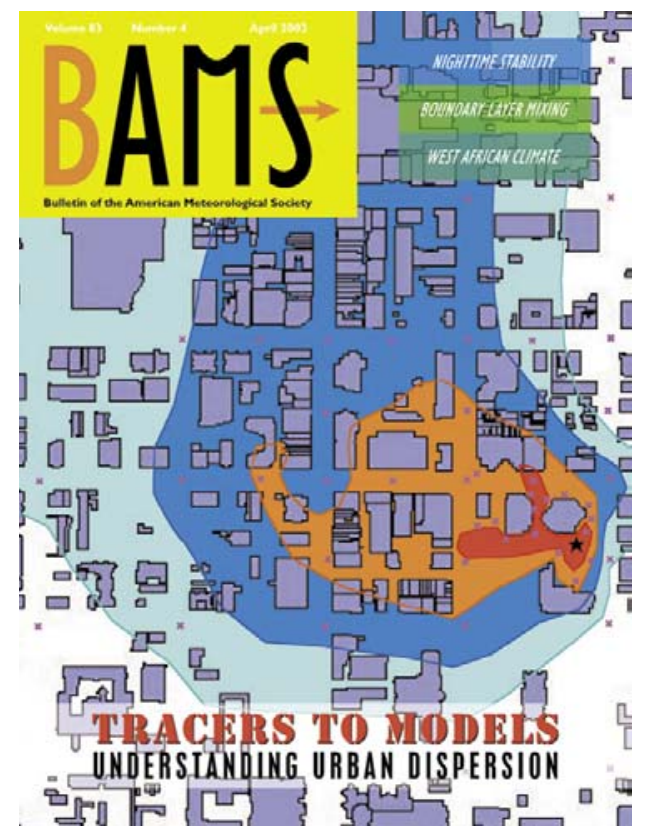

Figure 3.

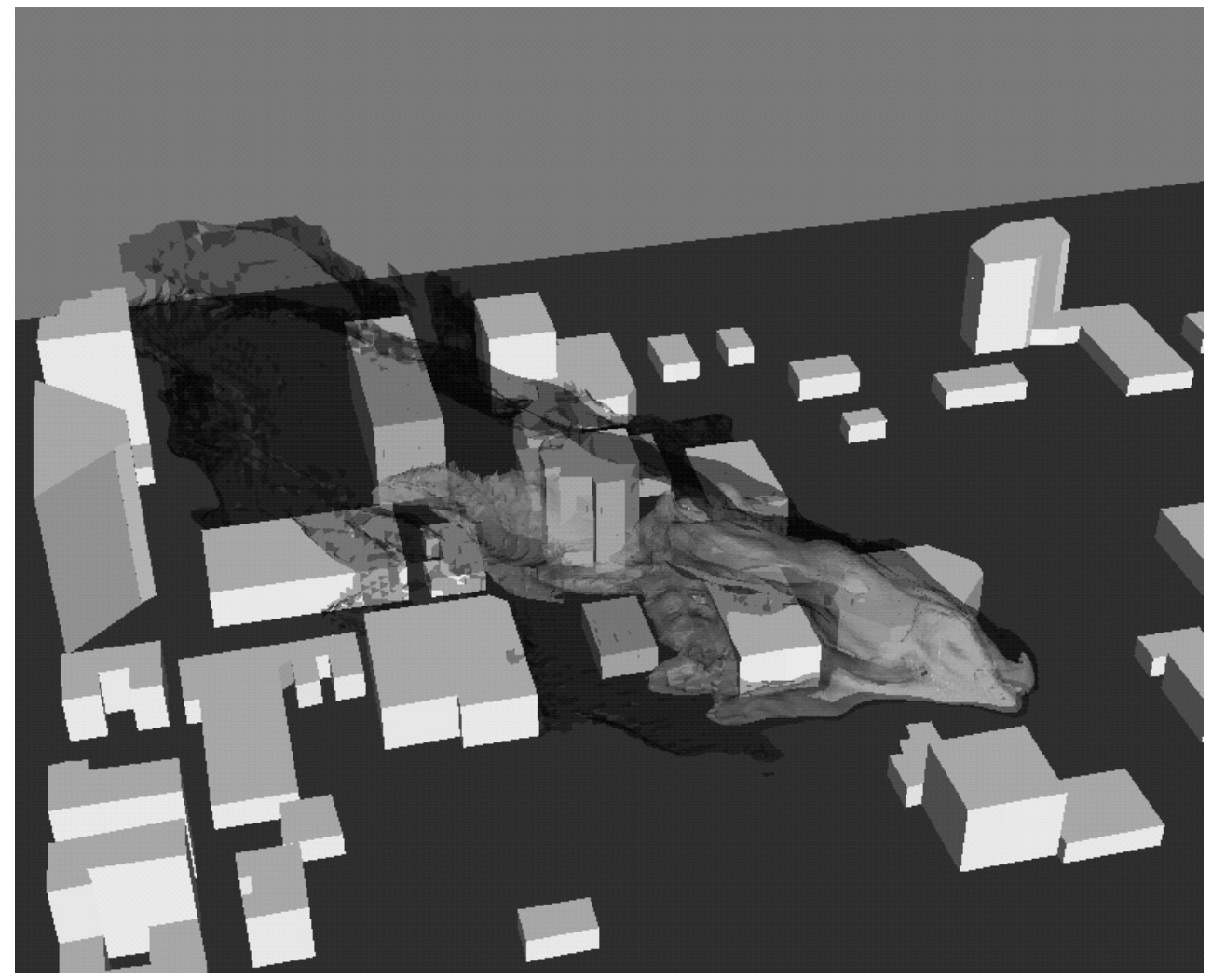


Figure 4.
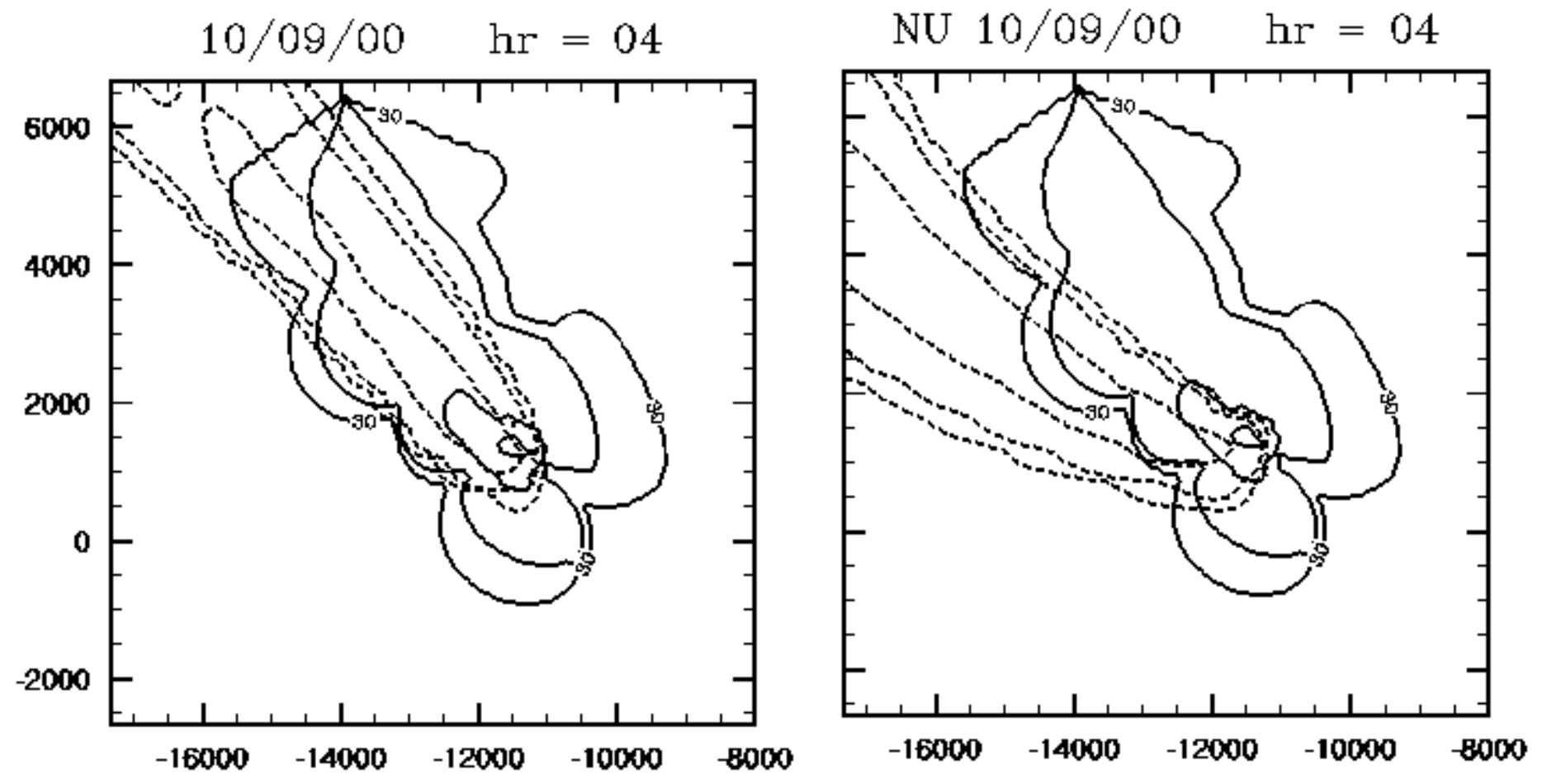
Figure 5.

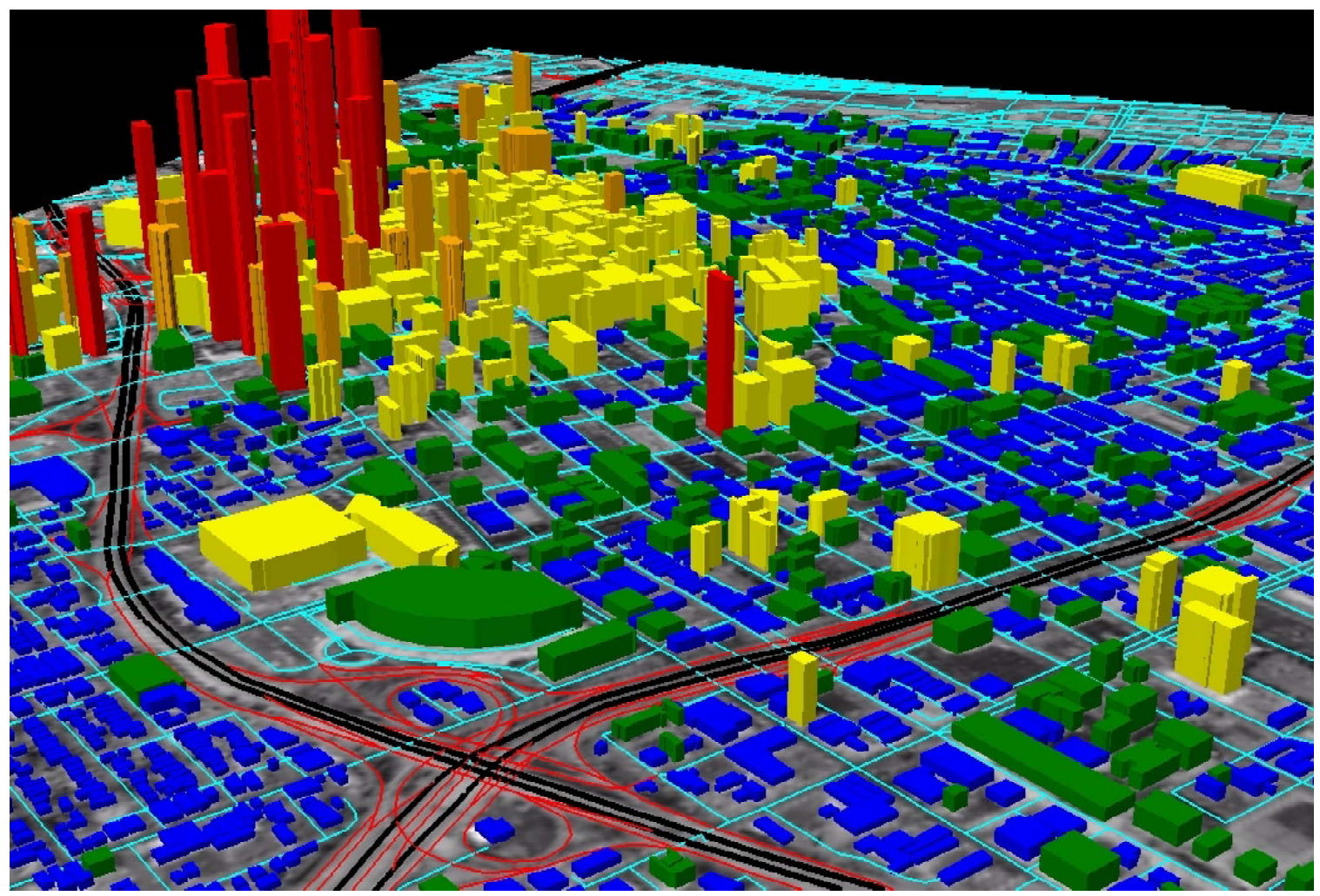

Figure 6.
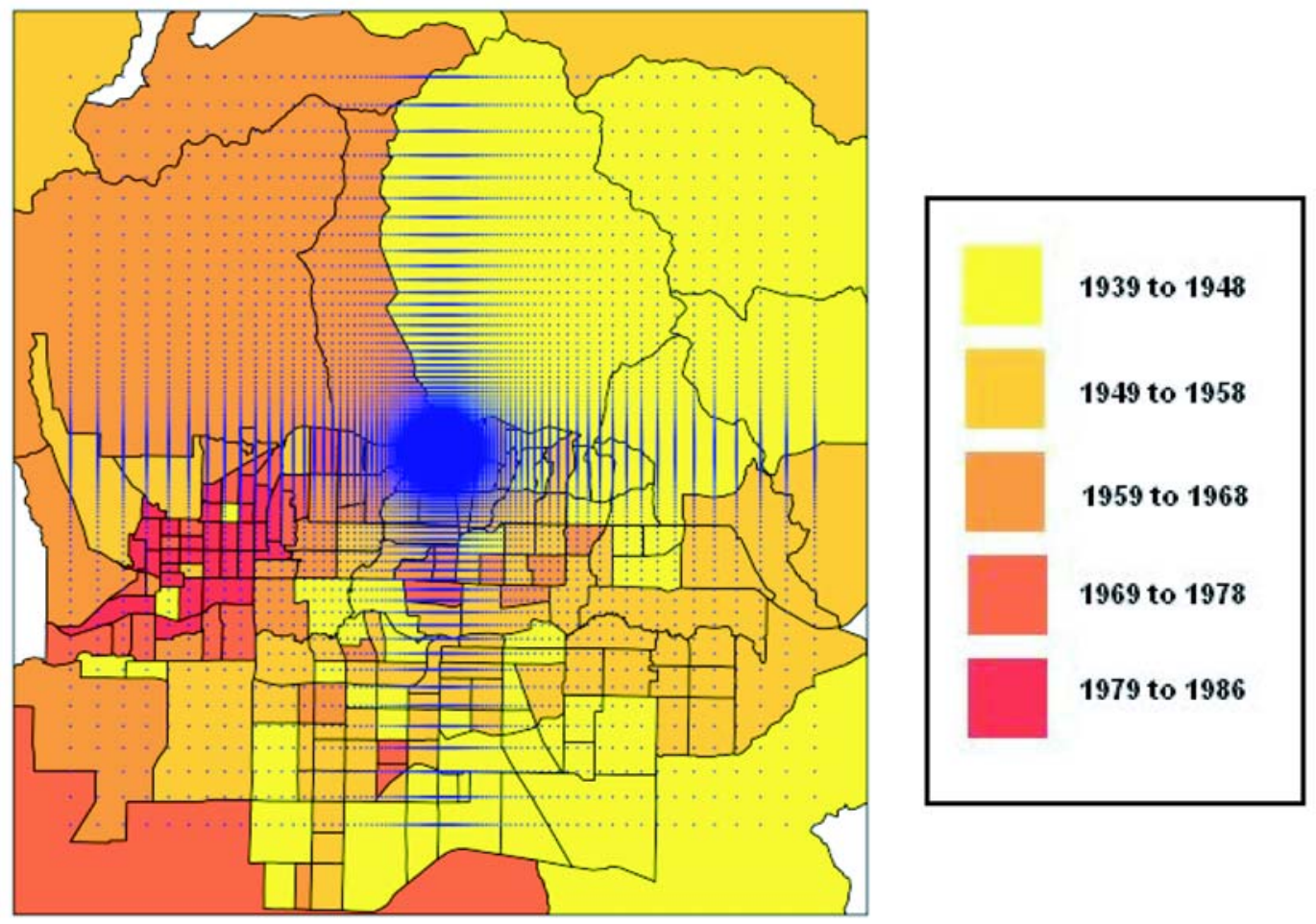
Figure 7.

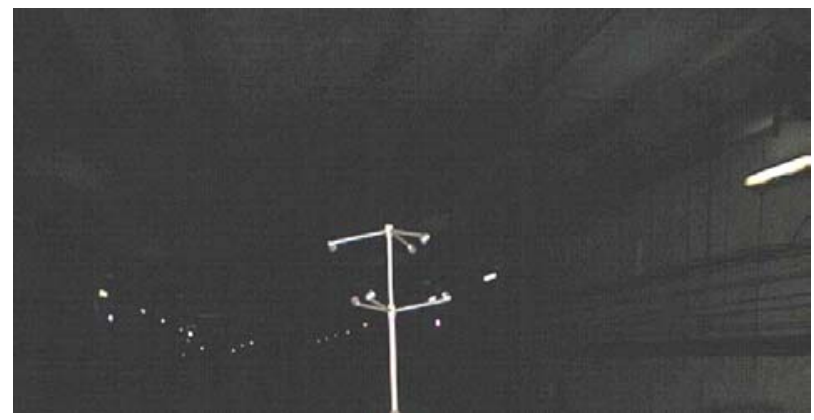

Figure 8.

Dose Response for Healthy and General Populations 2 Minute Exposure to Sarin

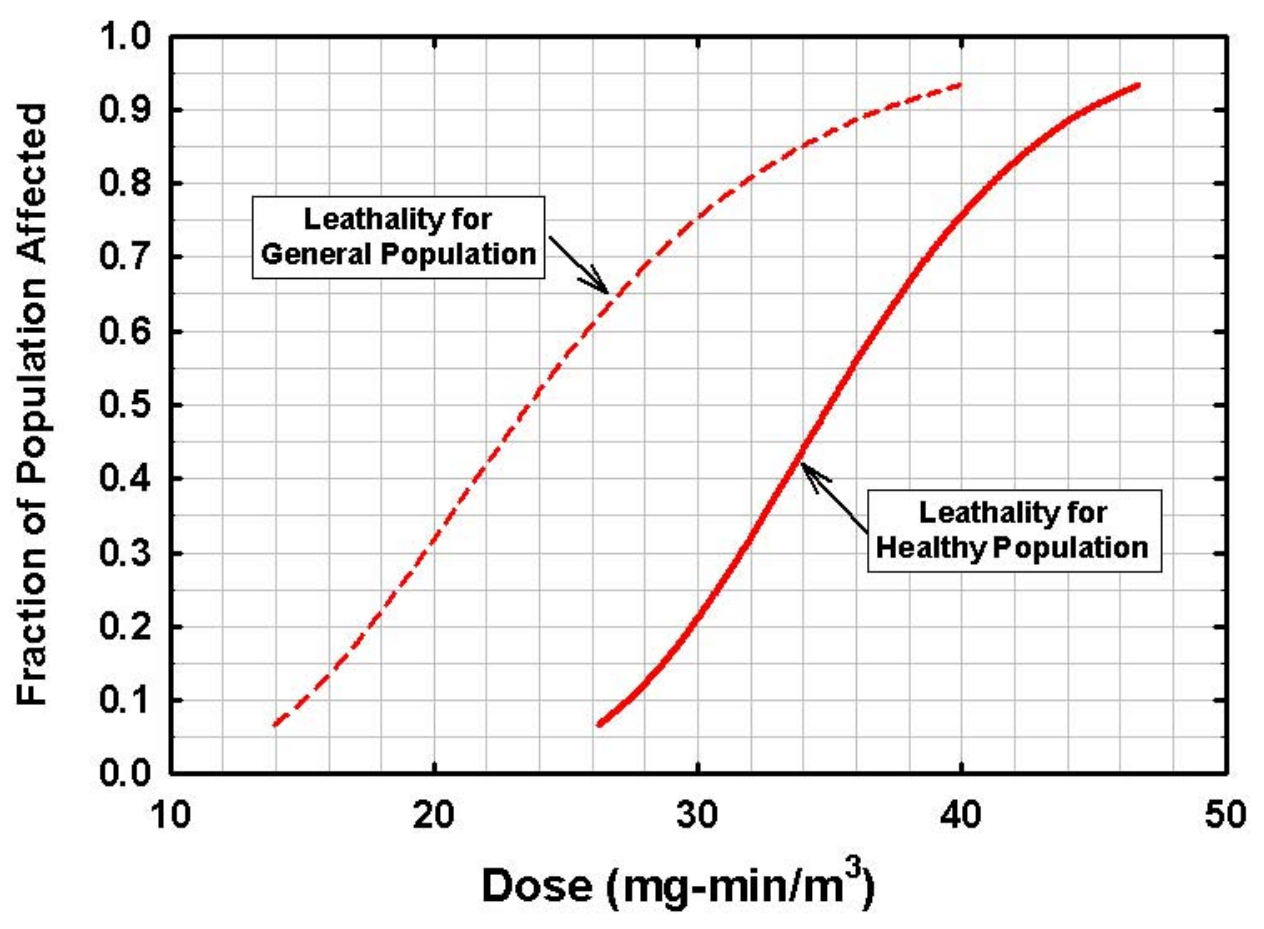

